Research Article

\title{
A proposal of AWS maintenance and periodic calibration tools and installation of ARGs for Radar QPE calibration
}

\author{
Masao Mikami ${ }^{*}$, Hiroyuki Ichijo', Koji Matsubara ${ }^{1}$, Le Xuan Duc ${ }^{2}$, Hoang Anh \\ Nguyen ${ }^{2}$ \\ ${ }^{1}$ Japan Meteorological Business Support Center; mikami@jmbsc.or.jp; \\ ichijo@jmbsc.or.jp; koth_matsubara@nifty.com \\ ${ }^{2}$ Viet Nam Meteorological and Hydrological Administration, \\ lexuanduc@gmail.com; hoanganhck@gmail.com \\ * Correspondence: mikami@jmbsc.or.jp; Tel.: +81-3-5281-0440
}

Received: 5 July 2020; Accepted: 21 August 2020; Published: 25 August 2020

\begin{abstract}
Automatic weather station (AWS) can automatically observe surface weather elements and can transmit the data to data center through internet or mobile phone lines. Therefore, it is suitable to monitor mesoscale disturbances and precipitation, in particular. Viet Nam Meteorological and Hydrological Administration (VNMHA) currently operates AWS and Automatic Rain Gauge (ARG) networks by multi-national donors. However, the instruments were not calibrated after installation, and it was difficult to perform maintenance on a regular basis, so technical problems often occurred in their observation accuracy and reliable operation. Japan-Vietnam joint technical project between Japan International Cooperation Agency (JICA) and VNMHA started in May 2018. As part of this project, the introduction of AWS maintenance and traceability technology, and ARG network for the calibration of radar rainfall quantitative estimation (QPE) were proposed. In this paper, we discuss the current situation of AWS and ARG network in VNMHA. Next, we will explain the maintenance and cyclic calibration of the instrument proposed in this project. Furthermore, we will explain the installation plan of the ARGs to calibrate two radar data in Phu Lien and Vinh for the development of QPE. Installation of ARGs has been achieved with cooperative works of VNMHA staffs and JICA experts. So, we introduce their activities for each step from site survey to pre-operational evaluation. Furthermore, we will discuss future issues for stable and accurate observations of AWS and ARG networks.
\end{abstract}

Keywords: Automatic Weather Station; Automatic Rain Gauge; Traceability; Calibration.

\section{Introduction}

With the invention of telegraph technology and the development of ground meteorological instruments, modern meteorological observations were started in various countries since the latter half of the $19^{\text {th }}$ century. As a result, quantitative surface meteorological observation data using hygrometers, barometers, and rain gauges with guaranteed traceability have been distributed to the world in near real time base.

The meteorological stations in each country simultaneously observe the surface meteorological elements every 3 to 6 hours and deliver them to each country. The establishment of a global simultaneous meteorological observation network made it possible to observe synoptic-scale meteorological disturbances with horizontal scales of 1,000 to 
$10,000 \mathrm{~km}$. For this reason, this surface meteorological observation is called "SYNOP surface observation" [1]. For better accuracy and more reliable SYNOP surface observation, World Meteorological Organization (WMO) has established the guideline of the observation environment of the observatory for synoptic meteorological observation [1]. As an example, Figure 1 shows the guideline of the layout of the observation station shown in [1]. In this way, by satisfying the standards set by WMO for the ground meteorological observations of each country in the world, it is possible to simultaneously perform world meteorological observations based on the same standard and the same accuracy.

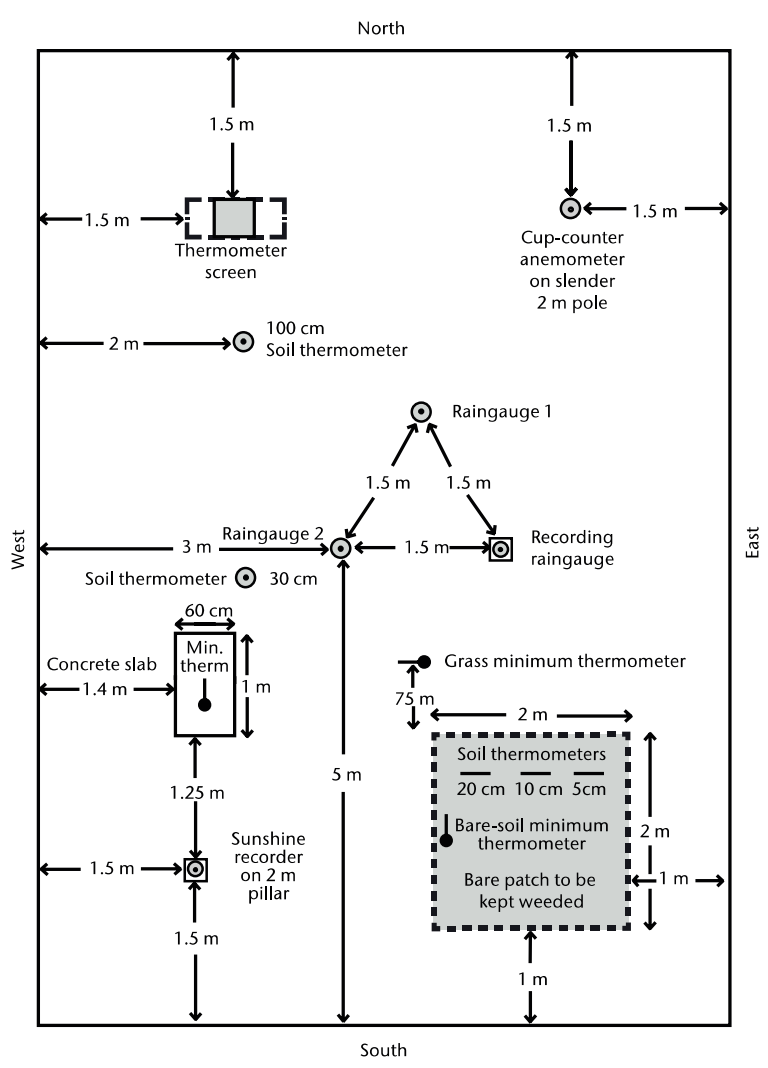

Figure 1. WMO layout design of surface observing station in [2].

The Vietnam Hydrometeorological service has a history of development for over 120 years. The first meteorological station was established in Nam Dinh Province on April 18, 1891. VNHMA has been conducted SYNOP observations based on WMO's surface meteorological observation guideline. Currently, 183 surface meteorological observation sites are operated by VNMHA in Vietnam. However, until recently, most of the surface observation was manned SYNOP observation. In recent years, technological innovations in measuring instruments have made it possible to automatically measure surface meteorological elements that were previously measured by observers. In addition, due to the progress of digital technology, Automatic Weather Station (AWS) has become popular. AWS collects data obtained by automatic measuring instruments and distribute them through mobile phones and/or internet. With the progress of these technologies, AWS has been rapidly introduced in many countries. In VNMHA, 191 sites of the AWS observation have been operated up to now. Figure 2 shows the site location map of AWSs in VNMHA. 


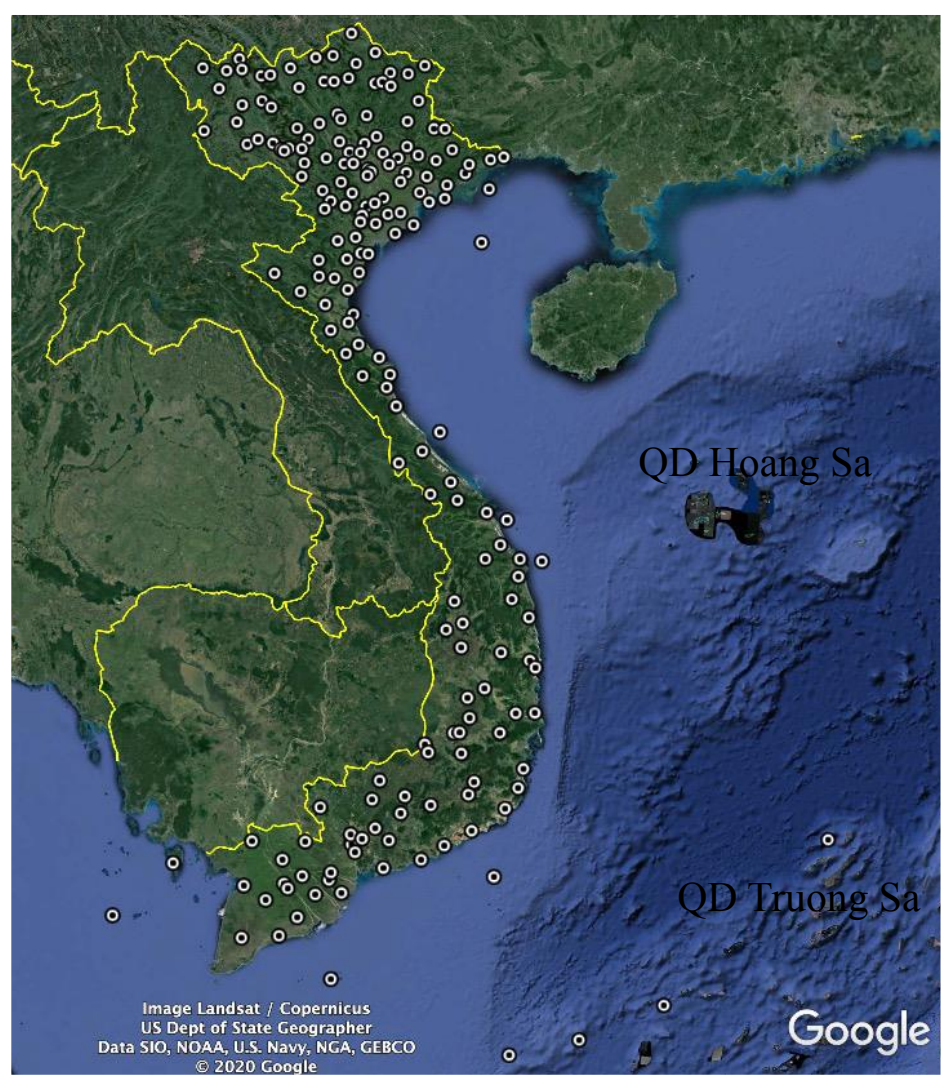

Figure 2. VNMHA AWS site location map.

The advantage of AWS observation can be summarized as follows: (1) Near real-time observation is possible. This enables to use AWS data for disaster early warning information such as heavy rainfall. (2) Frequent observation is possible. SYNOP observations are every 3 hours, but most AWS can operate at time intervals of 1 to 20 minutes. (3) Operation is automatically done. Therefore, it can be installed at many sites with fewer human resources. As a result, observations with higher spatial density than SYNOP observations are possible. And the observation information of high spatial density with short time intervals gives a great advantage in monitoring mesoscale disturbances such as heavy rainfall. (4) In terms of operation, the initial cost is high, but the operation cost is relatively low. (5) Even if there is a communication failure at the observation site, the data can be archived in AWS itself, and there is little risk of data loss. (6) Since AWS data are digital data, it is easy to process and analyze the AWS data and develop applications for various weather information. In summary, AWS observations have a great advantage over SYNOP observations in monitoring heavy rainfall associated with mesoscale disturbances.

On the other hand, the disadvantages of AWS observation are as follows: (1) Since AWS has unmanned observations installed at many sites, it is not easy to secure traceability by periodic verification by standard instrument. It is required to make periodical calibration of AWS instruments to maintain measurement accuracy. (2) Even though the operation of AWS is automatic, if maintenance of AWS system cannot be performed regularly, long-term stable operation will be difficult. (3) Since data transmission depends on the reliability of the network, data transmission is often interrupted in remote areas where the communication 
infrastructure is weak. (4) Data transmission from AWS is automatically delivered, so Quality Control (QC) by human check and Automatic Quality Control (AQC) at RHMC data center and IDC are required.

Thus, the stable and reliable operation of AWS requires (1) periodic maintenance of AWS system and calibration of AWS instruments and (2) QC at the observation site and AQC system at RHMC data center and Information and Data Center (IDC) in VNHMA.

Vietnam is a vulnerable country against natural disasters and has been suffered from damages by meteorological events especially for heavy rainfall. Typhoons and monsoons bring heavy/torrential rains to plains and steep mountain areas which bring about serious damage to Vietnam's society and economy. Based on this background, JICA and VNMHA started "the project for Strengthening Capacity in Weather Forecasting and Flood early warning system" (hereafter this project) on $31^{\text {th }}$ of May 2017.

Output 1 activity of this project aims to improve the maintenance and calibration capabilities of surface meteorological observation equipment, AWS rainfall information is used as (1) disaster prevention information such as warnings by monitoring the real-time rainfall distribution. In addition (2) it is also used to improve the accuracy and reliability of QPE by using rainfall data as ground truth to calibrate the rainfall estimated by the radar signal intensity from the $\mathrm{Z}-\mathrm{R}$ relationship. Therefore, improving the reliability and maintaining capacity of the rain gauge in AWS and ARG systems are a key issue for Output 1 and 2 of this project.

Based on the above consideration, the purposes of this paper are (1) to review the current situation of VNMHA's AWS network system, (2) to discuss the technical issues for operation of AWS and ARG systems with high accuracy and reliability that can be used for monitoring of heavy rainfall and for development of application such as QPE and (3) to propose a maintenance and calibration tools for AWS to improve the maintenance and calibration capabilities of AWSs in VNMHA.

\section{AWS systems in VNMHA}

\subsection{Current status of AWS systems in VNMHA}

In this project, in order to identify the current situation and issues to address for the output goals, first, a Base Line Survey (BLS) was conducted from June 4 to 29 in 2018. For this, the site survey was conducted at Mid-Central Regional Hydro-Met. Center (RHMC) in Da Nang as well as North-East RHMC in Hai Phong and North-Central RHMC in Vinh. Among them, North-East and North-Central RHMCs are the target regions in this project.

In Vietnam, the data of each AWS site are collected by IDC in VNMHA and then distributed to the forecast section. In BLS, field survey on the current situation of AWS observation was conducted at the three RHMCs.

It was found that different AWS systems are installed by different donors in each of the three RHMCs. In Mid-Central RHMC, AWSs made in Italy has been operated. In NorthCentral RHMC, AWSs made in Germany by World Bank (WB) donor are used. And in the North-East RHMC, AWSs made in Korea by Korean donors are used. At the time of the survey, AWSs of the WB were still in the long-term trial operation before the handover, and they were not used in the operation yet. Each AWS network is deployed only in their RHMC 
region with the exception of the WB donored AWSs in North-Central RHMC. All the AWSs data are sent to IDC in VNMHA via the data center in each of RHMCs. Currently, AWS data are mainly used only by each RHMC. For this reason, the management and operation of each AWS is carried out by each RHMC. However, after the defect warranty period by the donor is over, the cost of maintenance and repair of any AWS systems are not account for. Therefore, there remain problems in stable operation over a long period of time.

\subsection{Overview of AWS for each donor}

The AWS systems used in the three RHMCs we inspected in the BLS have different specifications. An outline of each AWS system is shown below.

\subsubsection{Korean AWS}

In North-East Region, AWS system made in Korea, which was donated by Korean International Cooperation Agency, has been operating since September 2015, and the 2-year warranty period has expired. AWSs are located at 25 sites within this region. Observation data are distributed to IDC via the data center of the RHMC in Hai Phong in real time basis. The specifications of the instruments used for observation of atmospheric pressure, air temperature, humidity, wind speed and direction, and precipitation are shown in Table 1.

Figure 3 also shows AWS system installed at Phu Lien meteorological station in NorthEast Region. Many AWSs in VNMHA are installed within the observation field of the SYNOP observatory. AWS in North-East Region sends the 10-minute average of atmospheric pressure, air temperature, relative humidity, wind direction, wind speed, and precipitation to IDC every 10 minutes.

Table 1. Specifications of Korea AWS instruments in North-East RHMC.

\begin{tabular}{|c|c|c|c|c|}
\hline Element & $\begin{array}{c}\text { Model } \\
\text { Number }\end{array}$ & Range & Accuracy & Comment \\
\hline $\begin{array}{l}\text { Atmospheric } \\
\text { Pressure }\end{array}$ & JYB400 & $500-1080 \mathrm{hPa}$ & $\pm 0.4 \mathrm{hPa}, 25^{\circ} \mathrm{C}$ & $\begin{array}{l}\text { Long term stability: } \\
\pm 0.5 \mathrm{hPa} / \text { year }\end{array}$ \\
\hline $\begin{array}{l}\text { Air } \\
\text { Temperature }\end{array}$ & JY100829 & $-40^{\circ} \mathrm{C}$ to $60^{\circ} \mathrm{C}$ & $\pm 0.3^{\circ} \mathrm{C}$ & \\
\hline Humidity & $\begin{array}{l}\text { Vaisala } \\
\text { HMP110 }\end{array}$ & $0-100 \%$ RH & $\begin{array}{l} \pm 1.7 \% \text { RH }(0-90 \% \\
\text { RH }), \pm 2.5 \% \text { RH }(90- \\
100 \% \text { RH })\end{array}$ & \\
\hline Wind Direction & JY-WD160C & $0-360^{\circ}$ & $< \pm 3^{\circ}$ & Resolution $2.8^{\circ}$ \\
\hline Wind Speed & JY-WS161D & $0-75 \mathrm{~m} / \mathrm{s}$ & $\pm 0.15 \mathrm{~m} / \mathrm{s}$ & \\
\hline Precipitation & JY100097-2 & $0-700 \mathrm{~mm} / \mathrm{h}$ & $\begin{array}{l} \pm 0.5 \mathrm{~mm}(0-20 \mathrm{~mm} / \mathrm{h}) \\
\pm 3 \%(>20 \mathrm{~mm} / \mathrm{h})\end{array}$ & $\begin{array}{l}\text { Diameter } 20.32 \mathrm{~cm} \text {, } \\
\text { Resolution } 0.5 \mathrm{~mm}\end{array}$ \\
\hline
\end{tabular}




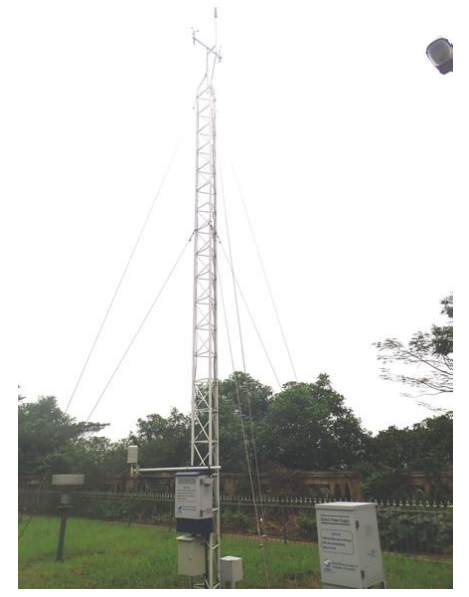

Figure 3. An appearance of Korea AWS observation station (Phu Lien Meteorological Radar Station).

The anemometer is a 3-cup anemometer type sensor with a wind speed range of up to $75 \mathrm{~m} / \mathrm{s}$ and an accuracy of $\pm 0.15 \mathrm{~m} / \mathrm{s}$. The wind vane has a resolution of $2.8^{\circ} \mathrm{C}$ and the accuracy of the wind direction is within $\pm 3{ }^{\circ} \mathrm{C}$. The thermometer is a Pt $100 \Omega$ type sensor, whose resolution is $0.1^{\circ} \mathrm{C}$, and accuracy is within $\pm 0.3^{\circ} \mathrm{C}$. The hygrometer uses Humicap (Vaisala, Type HMP110). The thermometer and hygrometer are contained in a natural ventilation type radiation shield (Figure 4a). For this reason, air temperature of AWS during calm to weak wind condition in sunny days may tends to be higher than the temperature of SYNOP observation, which is measured in a Stevenson screen box. Therefore, it is necessary to be careful when using daytime AWS temperature data [2]. The barometer is a digital barometer using a non-mercury type silicon sensor with microprocessor-based signal compensation process (Figure $4 \mathrm{~b}$ ). The accuracy is \pm 0.4 $\mathrm{hPa}$ at $25^{\circ} \mathrm{C}$ and long-term stability is $\pm 0.5 \mathrm{hPa} / \mathrm{Y}$ ear. The rain gauge is a tipping bucket type sensor with an opening diameter of $200 \mathrm{~mm}$, which has a measuring range up to $700 \mathrm{~mm}$ of hourly rainfall, and has a resolution of $0.5 \mathrm{~mm}$ (Figure 4c). It should be noted that the rain gauge sensor does not use windshield to prevent the reduction of rain capture rate due to wind, so rainfall data may tend to be affected by strong wind. For this, we need to be careful with precipitation data by this sensor when wind speed is high [3].

All sensor signals are logged to the data logger every 10 seconds, the data logger calculates the 10 minutes average value, and then transmits the averaged data to IDC every 10 minutes.

(a)

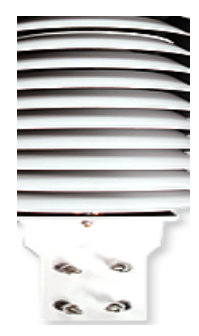

(b)

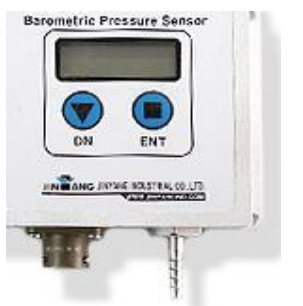

(c)

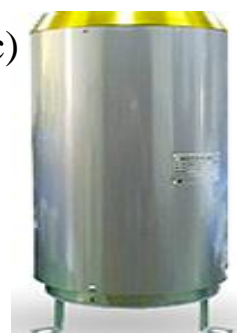

Figure 4. Sensors used in the Korean AWS: (a) air temperature and hygrometer sensors with radiation shield; (b) Ditigal barometeer and (c) rain gauge. 


\subsubsection{World Bank AWS}

In North-Central RHMC, AWS system designed in Germany, which was donated by WB, has been used. Totally 22 AWS sites are located in this RHMC. There are also 43 ARGs installed by WB's donor in this RHMC. Installation of the AWS and ARG systems were completed in 2017. However, at the time of the BLS (March 2019), these AWS systems were before handover and were in the field trial operation period. Nevertheless, observation data are distributed to IDC through mobile phone line every 10 minutes.

The specifications of the observation elements and instruments are shown in Table 2. And Figure 5a shows AWS system installed at Vinh meteorological station in North-Central Region.

Table 2. Specifications of World Bank AWS instruments.

\begin{tabular}{|c|c|c|c|c|}
\hline Element & Type & Range & Accuracy & Comment \\
\hline & $\begin{array}{l}\text { 5600-0120- } \\
\text { 3A/OTT } \\
\text { Hydromet. }\end{array}$ & $500-1100 \mathrm{hPa}$ & $\begin{array}{l}0.2 \mathrm{hPa} \text { at } 20{ }^{\circ} \mathrm{C} \text { and } 0.1 \\
\mathrm{hPa} \text { outside the heat } \\
\text { range }\end{array}$ & $\begin{array}{l}\text { Resolution: } 0.01 \\
\mathrm{hPa}\end{array}$ \\
\hline Air Temperature & OTT TRH & $-40^{\circ} \mathrm{C}-+80^{\circ} \mathrm{C}$ & $\begin{array}{l} \pm 0.1^{\circ} \mathrm{C} \text { at } 20^{\circ} \mathrm{C}, \pm 0.5^{\circ} \mathrm{C} \\
\text { at }-40{ }^{\circ} \mathrm{C}, 80^{\circ} \mathrm{C} \text { linearity }\end{array}$ & $\begin{array}{l}\text { Resolution: } \\
{ }^{\circ} \mathrm{C}\end{array}$ \\
\hline Humidity & OTT TRH & $0-100 \% \mathrm{RH}$ & $\begin{array}{l}\max . \pm 2 \% \text { RH }(0-90 \% \\
\mathrm{RH}) ; \max . \pm 3 \% \mathrm{RH}(90- \\
100 \% \mathrm{RH})\end{array}$ & Resolution: $0.1 \%$ \\
\hline Wind Direction & $\begin{array}{l}\text { Lufft V200A- } \\
\text { UMB }\end{array}$ & $0-360^{\circ}$ & $<3^{\circ}$ & Resolution: $0.1^{\circ}$ \\
\hline Wind Speed & $\begin{array}{l}\text { Lufft V200A- } \\
\text { UMB }\end{array}$ & $0.3-90 \mathrm{~m} / \mathrm{s}$ & $\pm 0.2 \mathrm{~m} / \mathrm{s}$ or $\pm 2 \%$ & Resolution: $0.1 \mathrm{~m} / \mathrm{s}$ \\
\hline Precipitation & Adon RG-Pro & $0-8 \mathrm{~mm} / \mathrm{min}$. & $\begin{array}{l} \pm 2 \% \text { with adjustable } \\
\text { rainfall intensity }\end{array}$ & $\begin{array}{l}\text { Orifice } 200 \mathrm{~cm}^{2} \text {, } \\
\text { diameter } 15.96 \mathrm{~cm} \text {, } \\
\text { Res. } 0.1 \mathrm{~mm}\end{array}$ \\
\hline
\end{tabular}

(a)

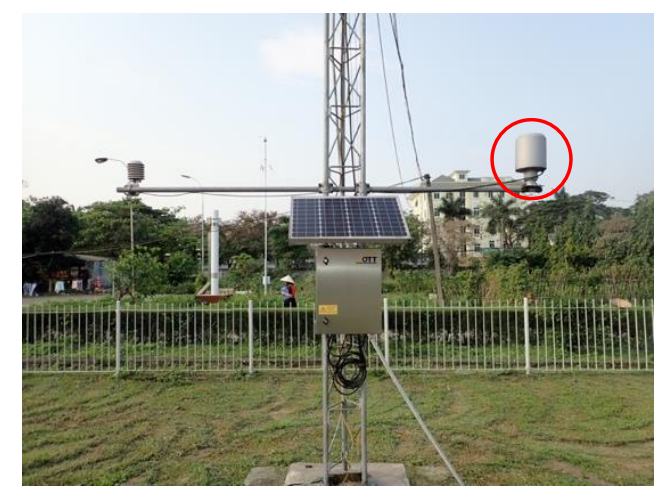

(b)

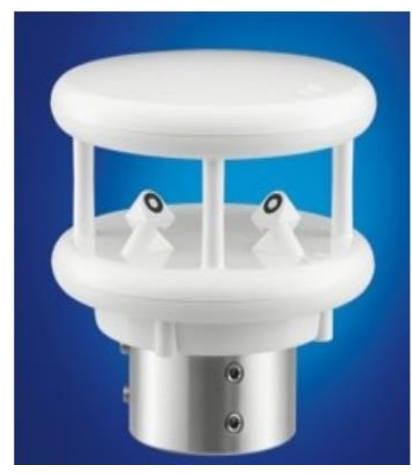

Figure 5. (a) An appearance of WB AWS system (Vinh Regional Hydro-Met Center). The rain gauge sensor is shown in red circle. And (b) wind speed and direction sensor settled at the top of the $10 \mathrm{~m}$ tower. 
As shown in Table 2, this AWS system measures surface pressure, temperature, humidity, wind direction, wind speed and precipitation. The wind sensor is an ultrasonic type sensor having maximum wind speed rang of up to $90 \mathrm{~m} / \mathrm{s}$ and the accuracy is $\pm 0.2 \mathrm{~m} / \mathrm{s}$ or $\pm 2 \%$ (Figure $5 \mathrm{~b}$ ). Compared to the 3-cup anemometer, the ultrasonic anemometer has less deterioration in measurement accuracy during long-term field use. The thermometer is a $\mathrm{Pt}$ resistance type sensor. The resolution, measuring range and accuracy are $0.01{ }^{\circ} \mathrm{C},-40$ to $+80^{\circ} \mathrm{C}$, and $\pm 0.1{ }^{\circ} \mathrm{C}$ at $20{ }^{\circ} \mathrm{C}$ and/or $\pm 0.5{ }^{\circ} \mathrm{C}$ at $-40{ }^{\circ} \mathrm{C}, 80{ }^{\circ} \mathrm{C}$, respectively. And the resolution, measuring rang and accuracy of the relative humidity sensor are $0.1 \%, 0$ to $100 \%$ $\mathrm{RH}$, and Max. $\pm 2 \% \mathrm{RH}(0$ to $90 \% \mathrm{RH})$ and Max. $\pm 3 \% \mathrm{RH}$ (90 to $100 \% \mathrm{RH})$, respectively. Both temperature and relative humidity sensors are settled inside the weather and radiation protection shield that protects the sensor from solar radiation, precipitation and wind (Figures $6 \mathrm{a}$ and $6 \mathrm{~b}$ ). The barometer is a resistive type sensor (Figure $6 \mathrm{c}$ ) and the resolution, measuring range and accuracy is $0.01 \mathrm{hPa}, 500$ to $1100 \mathrm{hPa}$, and $0.2 \mathrm{hPa}$ at $20^{\circ} \mathrm{C}$, respectively.

The rain gauge is a tipping bucket type sensor with an opening diameter of $15.96 \mathrm{~cm}$ with orifice of $200 \mathrm{~cm}^{2}$ and the resolution and maximum capacity are $0.2 \mathrm{~mm}$ and up to 16 $\mathrm{mm} / \mathrm{min}$ of precipitation, respectively (Figure 6d). Similar to the Korean AWS, this rain gauge does not come with windshield. In addition, this sensor is fixed to a pillar that extends horizontally from the center pole, and the ground clearance of the opening is $1.8 \mathrm{~m}$ in height (Figure 5a). For these reasons, it is considered that the capture rate of precipitation is considerably influenced by wind speed [3], and, similar to the AWS in North-East RMHS, it needs careful consideration when using precipitation data under strong wind. The data logger set inside the main body calculates the average values for 10 minutes and then sends the data to RHMC data center.

(a)

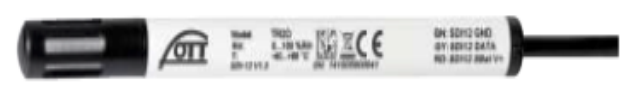

(c)

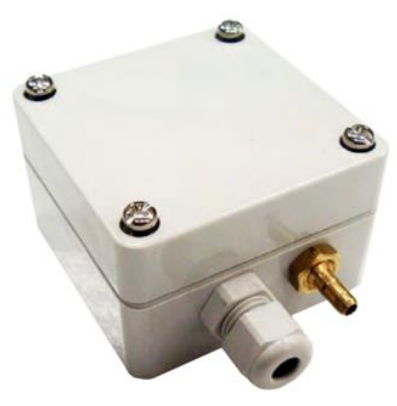

(b)

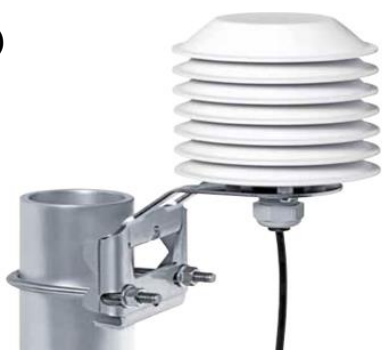

(d)

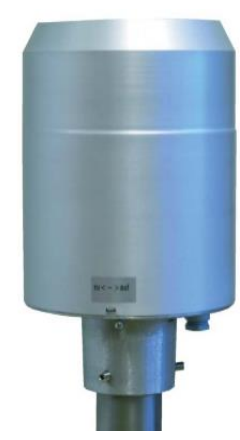

Figure 6. Sensors used in the World Bank AWS: (a) thermometer and hygrometer sensors; (b) radiation shield for thermometer and hygrometer; (c) digital barometer and (d) rain gauge. 


\subsubsection{Italian AWS}

In Mid-Central Region, SMP20 system by CAE Technology Company, donated by Italy, has been operated since 2010. Totally 17 AWS sites are located in this region. An original system by CAE technology is used for data network transmission and application for data viewer. And the management/display system application is installed only on one PC in the monitor room of the observation section of the Mid-Central Regional Center in Da Nang, and it is contractually impossible to copy and use it to other PCs at the same time. For this reason, at the time of the BLS, real-time information of the AWSs cannot be monitored by forecasting operation room or weather stations in Mid-Central RHMC. Therefore, real-time AWS information was not fully available for the forecast operation at that time.

Table 3. Specifications of Italy AWS instruments.

\begin{tabular}{|c|c|c|c|c|}
\hline Element & Type & Range & Accuracy & Comment \\
\hline $\begin{array}{l}\text { Atmospheric } \\
\text { Pressure }\end{array}$ & BA20 & $\begin{array}{l}600-1100 \\
\mathrm{hPa}\end{array}$ & $\begin{array}{l} \pm 0.3 \mathrm{hPa} \text { in range }-10 \text { to } \\
50^{\circ} \mathrm{C}\end{array}$ & $\begin{array}{l}\text { Sensitivity: Higher } \\
\text { than } 0.1 \mathrm{hPa}\end{array}$ \\
\hline Air Temperature & TU20 & $-30^{\circ} \mathrm{C}-+50^{\circ} \mathrm{C}$ & $0.27^{\circ} \mathrm{C}$ over the whole range & $\begin{array}{l}\text { Resolution: }<0.02 \\
{ }^{\circ} \mathrm{C}\end{array}$ \\
\hline Humidity & TU20 & $0-100 \% \mathrm{RH}$ & at $25^{\circ} \mathrm{C} ; \pm 2 \%(0-100 \%)$ & $\begin{array}{l}\text { Operating } \\
\text { teperature: }-20 \text { to } \\
50^{\circ} \mathrm{C}\end{array}$ \\
\hline Wind Direction & DV200 & $0-360^{\circ}$ & \pm 2 gradi & \\
\hline Wind Speed & VV200 & $0-180 \mathrm{~km} / \mathrm{h}$ & $\begin{array}{l}1 \mathrm{~km} / \mathrm{h}(0.27 \mathrm{~m} / \mathrm{s}) \% \mathrm{read} \\
\text { process }\end{array}$ & \\
\hline Precipitation & PMB2 & $0-300 \mathrm{~mm} / \mathrm{h}$ & $<3 \%$ up to $300 \mathrm{~mm} / \mathrm{h}$ & $\begin{array}{l}\text { Orifice }=1000 \mathrm{~cm}^{2} \\
\text { Diameter } 35.7 \mathrm{~cm}\end{array}$ \\
\hline
\end{tabular}

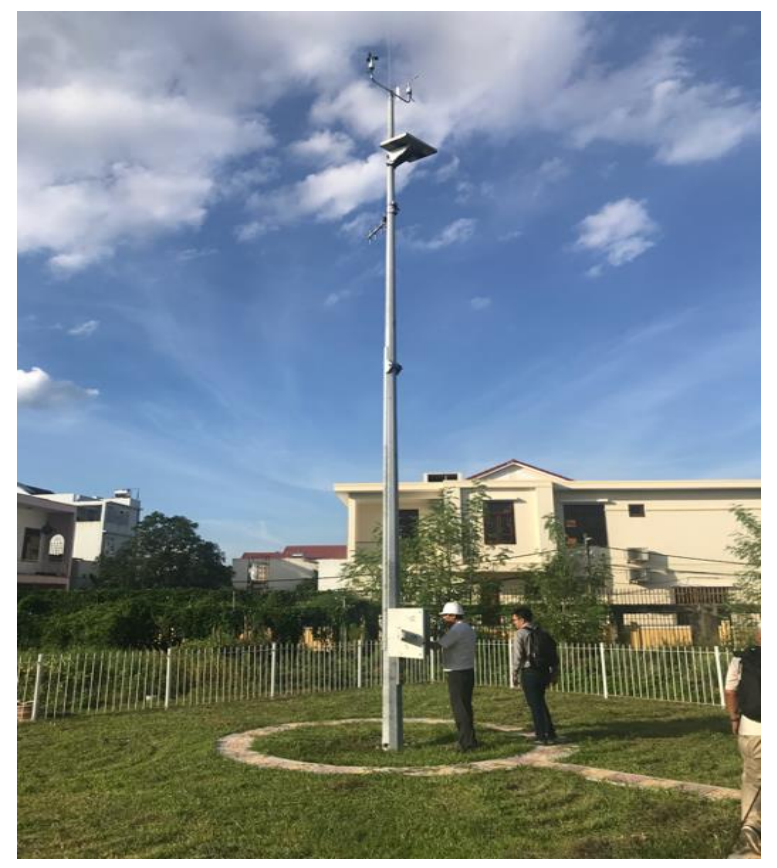

Figure 7. An appearance of Italian AWS system (Da Nang Regional Hydro-Met Center). 
The specification of the observation elements and instruments of this AWS system are shown in Table 3. Figure 7 shows AWS system installed at Da Nang meteorological station in Mid-Central Region. The temperature sensor is a Pt $100 \Omega$ type sensor, whose resolution, range, and accuracy are $0.02{ }^{\circ} \mathrm{C},-30$ to $50{ }^{\circ} \mathrm{C}$, and within $\pm 0.27{ }^{\circ} \mathrm{C}$, respectively. The hygrometer has an accuracy of $\pm 3 \% \mathrm{RH}$ and the measurement range are 0 to $100 \%$. Differ from other AWS system, both temperature and relative humidity sensors are settled inside a Stevenson screen box that can protect the sensor from solar radiation, precipitation and wind (Figures $8 \mathrm{a}-8 \mathrm{~b}$ ). The anemometer is a 3-cup type and has maximum range of 0 to $50 \mathrm{~m} / \mathrm{h}$ and the wind direction sensor has an accuracy of $\pm 2^{\circ}$.

(a)

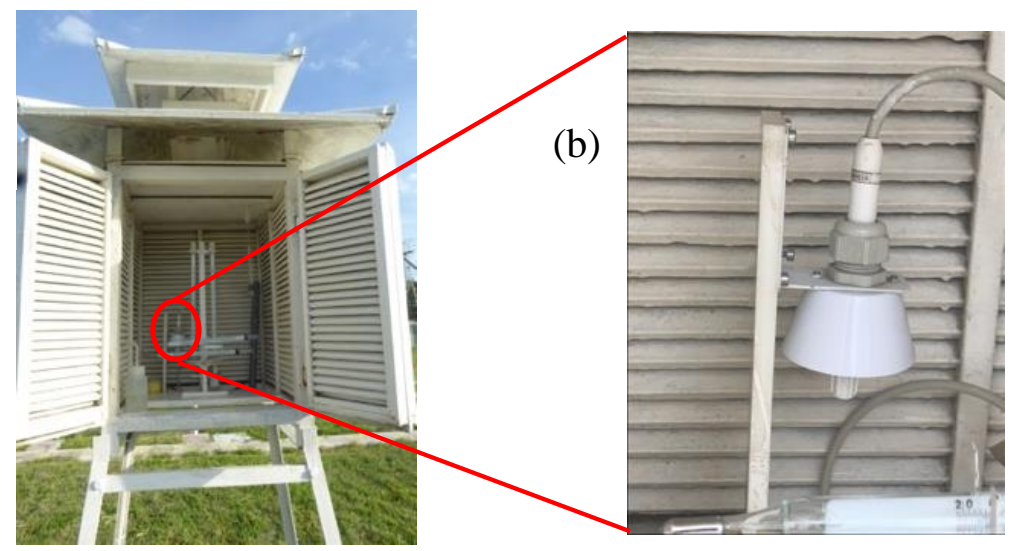

Figure 8. (a) Stevenson screen box for temperature and hygrometer, shown in red circle and (b) air temperature and hygrometer sensors of Italy AWS (Da Nang Regional Hydro-Met Center).

The barometer can measure 600 to $1100 \mathrm{hPa}$ of pressure with an accuracy of $\pm 0.3 \mathrm{hPa}$ $\left(-10\right.$ to $\left.50^{\circ} \mathrm{C}\right)$. This is a digital type sensor that is mercury free (Figure $\left.8 \mathrm{~b}\right)$. The rain gauge is a tipping bucket type sensor with an opening diameter of $35.7 \mathrm{~cm}$ with orifice of $1000 \mathrm{~cm}^{2}$ and the resolution and maximum capacity are $0.2 \mathrm{~mm}$ and up to $300 \mathrm{~mm} / \mathrm{h}$ of precipitation, respectively.

Similar to other AWS system, this rain gauge also does not come with wind shield (Figures 9a and 9b). Data collected by the AWS stations will be transmitted in real-time to the 5 Provincial Centers and Mid-Central RHMC in Da Nang, and then converge at IDC in VNMHA.

(a)

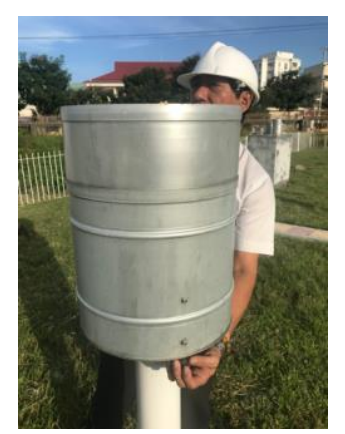

(b)

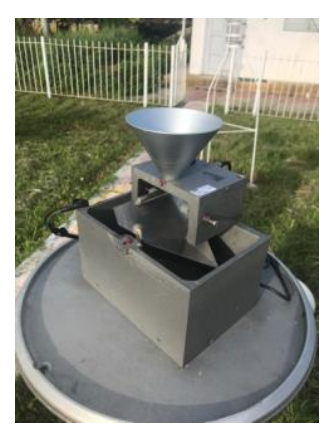

Figure 9. (a) Appearance and (b) inside view of rain gauge (PMB2) of Italian AWS (Da Nang Regional Hydro-Met Center). 


\subsubsection{Current situation of traceability and calibration of AWS instruments}

VNMHA has three Instrumentation Center for verification of SYNOP surface observation instruments in Hanoi, Da Nang, and Ho Chi Minh City. SYNOP instruments are regularly certificated by standard instruments with guaranteed traceability, and certification records are kept in every observatory. On the other hand, regarding the maintenance and traceability of the three AWS systems we have seen so far, initial certification was conducted at the VNMHA's instrument center before the installation of AWS at each site, and the traceability of each observation element is guaranteed at the time of installation. However, after installation, periodic maintenance and calibration of AWSs have not been properly done.

In order to test the current measurement accuracy of AWS observation equipment and to examine the possibility of implementing on-site traceability, comparison of the barometer used in AWS with the Vaisala PTB330 type barometer, whose accuracy was confirmed by the Japan Meteorological Agency (JMA), was conducted at Uong Bi Observatory and at North-Central RHMC in Vinh. Using the Vaisala digital barometer type PTB330 brought from Japan as a reference, comparative measurements with two AWS barometers were performed, and the results shown in Table 4 were obtained. The minimum display digit of the pressure value shown in the data logger of WB AWS is one digit in hPa. For use in periodic calibration, it is necessary to display at least one digit in $0.1 \mathrm{hPa}$, which is recommended in [1].

Table 4. Results of comparative measurement of barometer.

\begin{tabular}{lcc}
\hline Target barometer & Korea Barometer & WB Barometer \\
\hline Location & Uong Bi & Vinh \\
Index error $(\mathrm{hPa})$ & +0.6 & +1 \\
\hline
\end{tabular}

From this result, it was also found that the calibration of AWS instruments can be done by performing comparative measurement at the AWS site using traveling standard instruments as a reference, whose traceability is guaranteed by VNMHA, as in this case.

\subsection{Issues found by the Base Line Survey}

In June 2018, we have conducted the BLS for understanding the current situation of VNMHA's AWS system as a part of the activity of this project. For this purpose, we have inspected the SYNOP and AWS sites in North-East, North-Central, and Mid-Central RHMCs. It is found that in order to enhance the reliability and accuracy of AWS in VNMHA, the following issues were summarized as challenges for this project. (1) AWS of each donor has not been subjected to periodic verification by VNMHA and/or calibration by intercomparison using the traveling standard after the pre-installation verification at the VNMHA headquarters. (2) Response at the occurrence of a technical trouble is guaranteed by the donor during the warranty period. Response after that is managed by each RHMC. However, periodic maintenance and calibration require more human resource. (3) No metadata record has been retrieved for each AWS site. In order to maintain the long-term reliability of AWS system, it is necessary to archive the periodic maintenance report as metadata historical 
record. (4) No equipment is available at AWS sites to perform maintenance and calibration after AWS installation. In addition, at present, there is not enough opportunity for the staff of the meteorological observatory to take lecture and training on AWS system maintenance and calibration procedures for AWS sensors.

\section{Introduction of a unified digital maintenance report and calibration tools for AWS}

As mentioned in the introduction, AWS is expected to play an important role in monitoring severe weather event such as heavy rainfall and strong winds associated with mesoscale meteorological disturbances. And based on the consideration of current situation of AWS systems in VNMHA discussed in 2.3, it was proposed to practice actions in this project as counter measures of enhancing reliability and accuracy of AWS measurement in VNMHA. In the following sections, we will explain the measures proposed in this project in detail.

\subsection{Introduction of unified digital maintenance report for AWS system}

In VNMHA's SYNOP observations, metadata report, such as verification history of measuring instruments, changes in the observation environment, changes and updates of measuring instruments, staff changes, etc., has been regularly recorded at the observation site. However, AWS does not have a similar metadata record. Since AWS automatically operates and observes, it is difficult to detect a trouble in advance, unless regular inspection and maintenance are performed. With periodic AWS system maintenance and calibration for instruments, we may take timely countermeasures without missing a data.

In addition, VNMHA has introduced different AWS systems by multiple donors. However, for AWS maintenance, it is desirable to establish a unified maintenance system nationwide. That is, it is desirable to record the regular maintenance based on the unified maintenance form. It is also desirable that the inspection report is shared as a digitized report at VNMHA's AWS supervisory department, nine RHMCs and AWS observatories, which will have a great advantage in managing long-term stable operation of AWS. For these reasons, in this project, it was proposed to use a report form on MS-EXCEL format. Because, this report can save as a digital file. Then, it is easy to share this report among each VNMHA's office.

Since 1 November 1974, the JMA has installed approximately 1300 ARGs throughout Japan, of which 840 are AWSs that observe wind direction/speed, temperature, and sunshine duration hours in addition to precipitation. JMA named these systems as AMeDAS (Automated Meteorological Data Acquisition System) and regularly conducts on-site inspections, which enable to keep the missing rate quite low. Similar to this, regarding AWS maintenance in VNMHA, we proposed to establish a maintenance report form as shown in Figures 10a and 10b with reference to the JMA inspection items. This maintenance report is designed to be selectively input the results of each check items with the toggle button (normal, abnormal, etc.). Then, we can immediately send a maintenance report by e-mail to the regional center and VNMHA's AWS supervisory department and can share the problem as soon as possible. And we will be able to find a technical issue and its solution more quickly and accurately. 
(a)

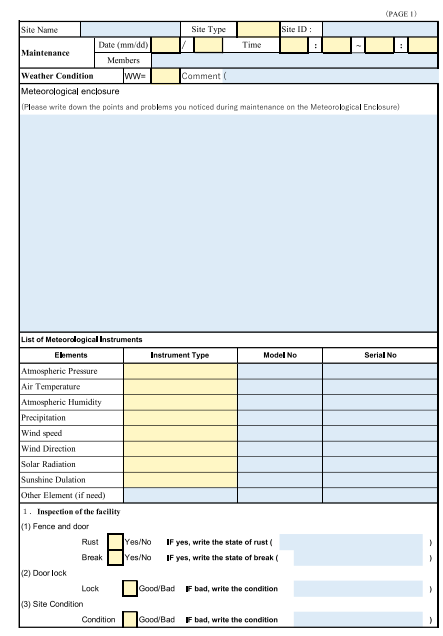

(b)

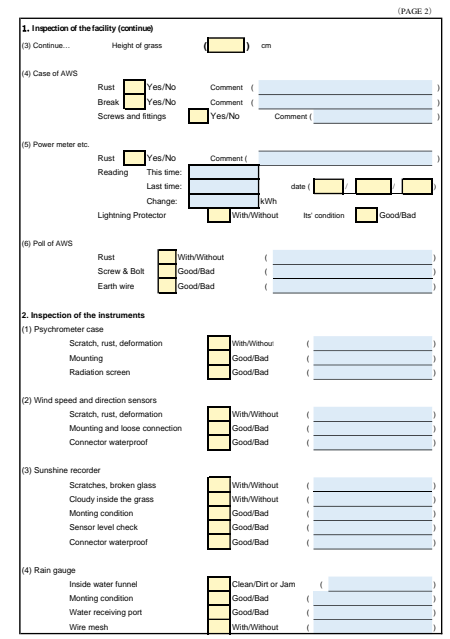

Figure 10. Examples of unified AWS maintenance report form (a) page 1 and (b) page 2.

\subsection{Introduction of calibration tools for periodic calibration of AWS instruments}

The major observation items of the AWS operated by VNMHA are precipitation, air temperature, humidity, wind direction and wind speed, and atmospheric pressure. These six meteorological elements are essential information for the surface weather condition and are important information for disaster prevention.

An important target of this project is introduced the radar QPE technology. For this purpose, it is necessary to adjust the parameters of the $Z-R$ relation equation using the radar signal intensity, $Z$, and precipitation, $R$. For this reason, the stable and accurate operation of precipitation observation by AWS and ARG are important mission of Output 1 activities of this project.

In this project, we proposed to use four sets of highly accurate and portable sensors for calibration of precipitation, air temperature, humidity, and atmospheric pressure sensors. These tools will be used at periodic AWS maintenance. Before using these calibration tools, they are verified at the instrument center of VNMHA to ensure traceability. As a result, it is possible to ensure traceability by performing comparative measurement between the AWS sensors and the calibration tools. Below, we introduce calibration tools for atmospheric pressure, air temperature, humidity, and precipitation sensors.

\subsubsection{Digital Barometer}

For on-site calibration of AWS barometer, a portable type digital barometer, Vaisala PTB-330TS will be used. This instrument can accurately measure atmospheric pressure with accuracy of $\pm 0.10 \mathrm{hPa}$ at $20^{\circ} \mathrm{C}$.

The verification of PTB-330TS will be done at the VNMHA instrument center before using this tool for calibration of the AWS barometer at each AWS site during periodic inspection. An overview of the device is shown in Figure 11 and a specification is shown in Table 5a. 


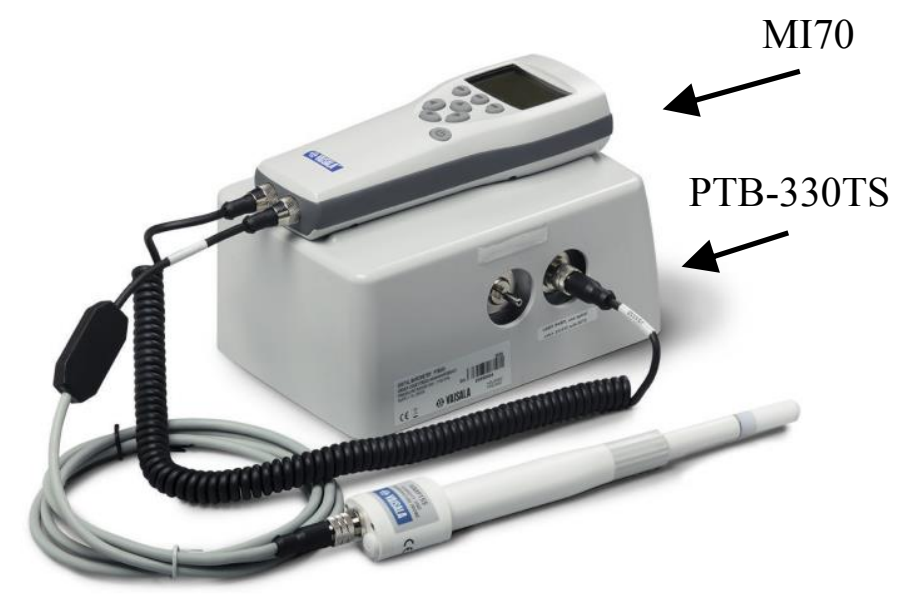

Figure 11. Portable digital barometer (Vaisala PTB-330TS) attached with controller MI70.

\subsubsection{Digital Assmann Ventilating Psychrometer}

Assmann ventilating psychrometers are widely used at surface meteorological observation site because of their high accuracy in measuring temperature and humidity. In general, Assmann ventilating psychrometer has a double radiation shield, which protect thermometer body from infrared radiation effect, and is forcedly ventilated in the space between the shield and the thermometer body, so heat effect due to solar radiation can be negligible. For this reason, we decided to use an Assmann ventilating psychrometer (JS-410) as a periodic calibration tool for AWS temperature and humidity sensors.

(a)

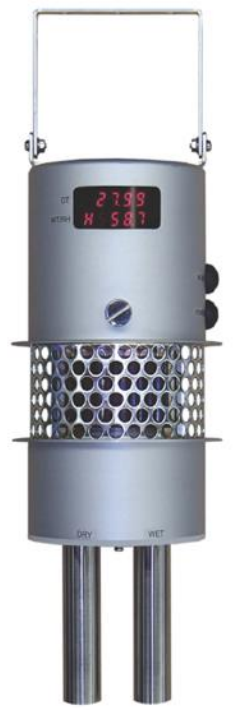

(b)

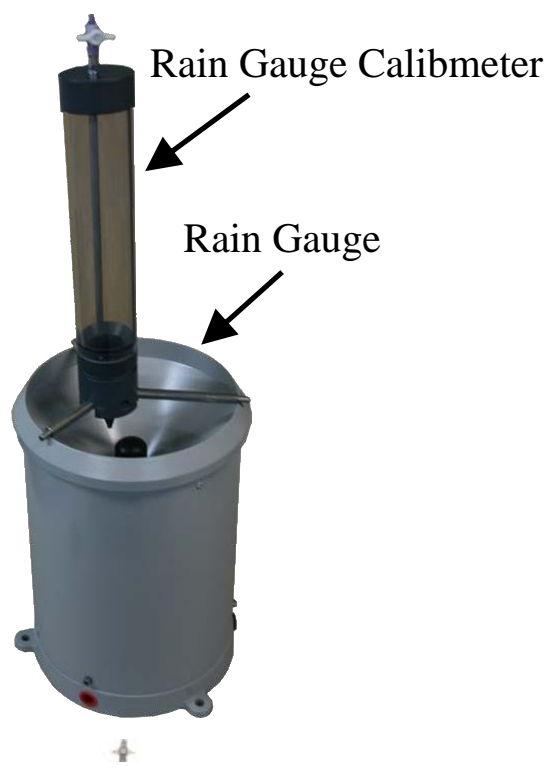

Figure 12. (a) Digital Assmann ventilating psychrometer (JS-410) and (b) rain gauge calibmeter (FCD-653).

In recent years, a digital Assmann ventilating psychrometer that uses a platinum resistance thermometer as a temperature sensor has been developed in place of the manual Assmann ventilation psychrometer that requires the observer to read the temperatures of dry and wet bulb temperature manually by eye. This is because there is no reading error by the 
observer, and it has a monitor screen that displays the wet and dry bulb temperatures and relative humidity, and the data is recorded in the micro-SD memory inside the main body, so it is possible to minimize human error. For ensuring traceability of temperature sensors, periodic verification is recommended using Thermostat Water Chamber, which will be procured by this project. An overview of the digital type Assmann ventilating psychrometer adopted in this project is shown in Figure 12a and the specification is shown in Table 5b.

Table 5. Specifications of AWS calibration tools; (a) Digital barometer, (b) Digigal Assmann psychrometer, and (c) Rain gauge calibmeter.

(a)

\begin{tabular}{ll}
\hline \multicolumn{1}{c}{ Item } & \multicolumn{1}{c}{ Specification } \\
Range & $800-1100 \mathrm{hPa}$ \\
Accuracy & $\pm 0.1 \mathrm{hPa}$ \\
Stability & $\pm 0.1 \mathrm{hPa} /$ year \\
& \\
Display & $\mathrm{LCD}$ display \\
Operating range & $-10-+40^{\circ} \mathrm{C}$ \\
Output & $0-1 \mathrm{~V}$ \\
& \\
\hline
\end{tabular}

(b)

\begin{tabular}{ll}
\hline \multicolumn{1}{c}{ Item } & \multicolumn{1}{c}{ Specification } \\
\hline Sensor & Pt $100 \Omega$ \\
Range & $-30-+50^{\circ} \mathrm{C}$ \\
Resolution & $0.01^{\circ} \mathrm{C}(\mathrm{dry})$, \\
& $0.1 \% \mathrm{RH}$ \\
Display & $\mathrm{LCD}$ display \\
Ventilation & Sirocco fan \\
Ventilation & $4-6 \mathrm{~m} / \mathrm{s}$ \\
speed & \\
\hline
\end{tabular}

(c)

\begin{tabular}{ll}
\hline \multicolumn{1}{c}{ Item } & \multicolumn{1}{c}{ Specification } \\
\hline Body & Portable type \\
Volume & $653 \mathrm{~mL}$ \\
Nozzle & $100 \mathrm{~mm} / \mathrm{h}, 300$ \\
& $\mathrm{~mm} / \mathrm{h}$ \\
Size $(\mathrm{mm})$ & $400 \times 290 \times 100$ \\
Weight & $2.0 \mathrm{~kg}$ \\
\hline
\end{tabular}

\subsubsection{Rain Gauge Calibmeter}

Unlike other meteorological factors, precipitation has low spatiotemporal uniformity, and precipitation phenomena do not always occur. Therefore, it is not realistic to carry out comparative observation of rain gauges for actual precipitation during inspection period. For this reason, calibration of rain gauges during inspection period will be carried out using a calibration device. In this project, we will introduce rain gauge calibmeter, HyQuest Solutions FCD-653 (Figure 12b).

This device consists of a transparent cylinder with a capacity of $653 \mathrm{ml}$ and a nozzle that screwed into the bottom of the cylinder. A pre-set volume of water will discharge to the tipping bucket rain gauge. This process is to be repeated a second time for an accurate calibration check. In order to confirm that the results come within the acceptable range, the number of tips will be manually counted or stored on the data logger and then compared with the total volume of water dropped from FCD 653. Two types of nozzles are available: 100 $\mathrm{mm} / \mathrm{h}$ and $300 \mathrm{~mm} / \mathrm{h}$ rainfall intensity, respectively. This makes it possible to confirm the linearity of rain gauge data with respect to rainfall intensity. The specification of this device is shown in Table 5c.

\subsection{Analysis of continuity of observation from SYNOP to AWS}

Wind speed, temperature, and humidity in the surface boundary layer, from surface to 20 to $50 \mathrm{~m}$ in height, have a strong height dependency, and the catching rate of the rain gauge strongly depends on the wind speed, too. For these reasons, if the heights and/or site location of the rain gauge, anemometer, and thermo-hygrometer will change, precipitation, wind speed, temperature, and relative humidity data will be suffered non-negligible effect [4]. 
Changes of sensor type and/or in the location of sensor may also have a significant effect on the observation data.

In recent years, in VNMHA, the surface meteorological observation is shifting from manned SYNOP observation to AWS observation. In that case, even if AWS is installed in the same observation field, the sensor type, location, and sensor height are generally different. Surface meteorological observation has a mission not only to monitor nowcasting for meteorological disaster prevention but also to monitor long-term climate change. Therefore, when the surface meteorological observation is changed from SYNOP to AWS, in order to ensure the continuity of observation, it is necessary to check its continuity and, if needed, to correct the AWS observation data.

Double mass analysis is a simple analytical method to inspect the continuity of rain gauge observations and correct the data [5]. In this project, we have practiced training on double mass analysis to members of the working group of the surface meteorological observations.

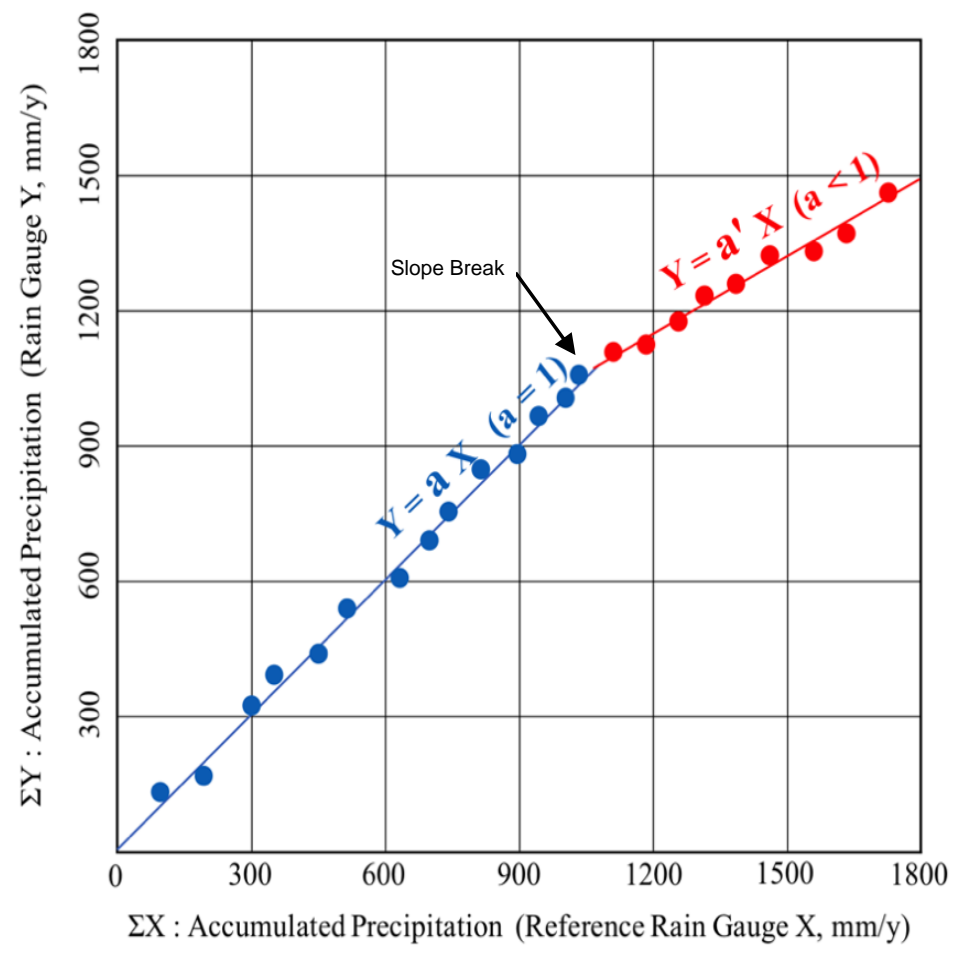

Figure 13. An example of double mass plot of rain gauges $X$ and $Y(\mathrm{~mm} / \mathrm{y})$.

The consistency of a rainfall record can be tested with double-mass analysis, which compares the cumulative annual (or alternatively, seasonal) value of station $\mathrm{Y}$ with those of a reference rain gauge $X$. In this case, the reference rain gauge is the SYNOP rain gauge adjacent to the AWS rain gauge. This method compares the cumulative annual (or alternatively, seasonal) value, $\Sigma Y$, of rain gauge $\mathrm{Y}$ with those, $\Sigma X$, of a reference rain gauge $X$. The cumulative pairs (double-mass values) are plotted in an $\mathrm{x}-\mathrm{y}$ arithmetic coordinate system (Figure 13). If the relation between $X$ and $Y$ is linear, the relation of $Y=\mathrm{a} X$ is obtained. And if $a=1$, it can be said that there is no difference in the measurement of both rain gauges. If $a$ is not equal 1 , the observation of rain gauge $Y$ is underestimated $(a<1)$ or overestimated (a $>1$ ) compared with reference rain gauge X. Also, if the plot shows a "slope break" (Figure 
13), the observation at station $Y$ has been inconsistent with the reference rain gauge since the slope changed and should be corrected.

\subsection{Seminar and training on maintenance and calibration of AWS for observatory staff}

In order to perform reliable and accurate AWS observation, it is necessary to keep AWS in good condition so that each sensor and each part of the AWS system can function properly. For that purpose, it is not enough to carry out a maintenance and comparative observation check according to a set procedure on the manual. For example, questions such as "has there been any change in the system status compared to the previous maintenance record?" and "what will be the cause?" are important attitude in advance to the inspection. Such consideration may lead to the early detection of instrument abnormality. In addition, "why a significant difference was observed in comparative observation?", such consideration may deepen the understanding of meteorological phenomenon and of the meaning of the observed data.

Therefore, this project has conducted training and seminars on the surface meteorological observation technology for VNMHA's WG members and staff. The contents are (1) the introduction of the WMO surface meteorological observation guideline, (2) an introduction of the atmospheric boundary layer near the surface, which has different characteristics from the free atmosphere, and (3) the introduction of principles and features of various meteorological observation instrument. Hereafter, we would like to share these training materials to the staff who could not attend the training and seminars.

In the training in Japan from June to July 2019, experts from JMA conducted a lecture on the meteorological agency's surface meteorological observation technology and practiced the training on the calibration of AWS instruments using periodic calibration tools proposed in this project. And we will plan to perform On the Job Training (OJT) for AWS periodic maintenance and calibration at the AWS sites in the North-East and North-Central RHMCs using these calibration tools.

\section{Installation of ARG for radar data calibration}

This section presents installation of ARGs for the calibration of two radars located at Phu Lien and Vinh towards upcoming QPE. The ARG installation is planned as one of the activities in this project, which is tightly linked to advanced activities such as accurate precipitation estimates based on QPE and development of Mobile Website in the JICA project. JICA expert team designed an implementation plan consists of five steps, i.e. survey, design, preparation, installation and evaluation based on their experiences in ARG installation in other countries. Based on this implementation plan, JICA experts promoted various practical works in cooperation with VNMHA staffs. The following sections give an outline of their remarkable works.

\subsection{Survey}

From the outcome of the BLS in June 2018, it was confirmed that all ARGs should be installed at VNMHA observation stations and that ARG data should be collected at real time by VNMHA headquarters in Hanoi. 
To find candidate stations within coverages of Phu Lien and Vinh Radars, radar-beam shadow diagrams shown in Figures $14 \mathrm{a}$ and $14 \mathrm{~b}$ were used.

Site survey of 20 candidate stations had been implemented for 15 days. The survey consists of 47 check items technically inclined and staff interview mainly about operation and natural disaster risks around the station. Survey results and recommendation of ARG installation sites (stations) were reported to VNMHA and then ARG installation at 18 ARG sites was approved in December 2018. 18 ARG installation sites are shown in Figure 15.
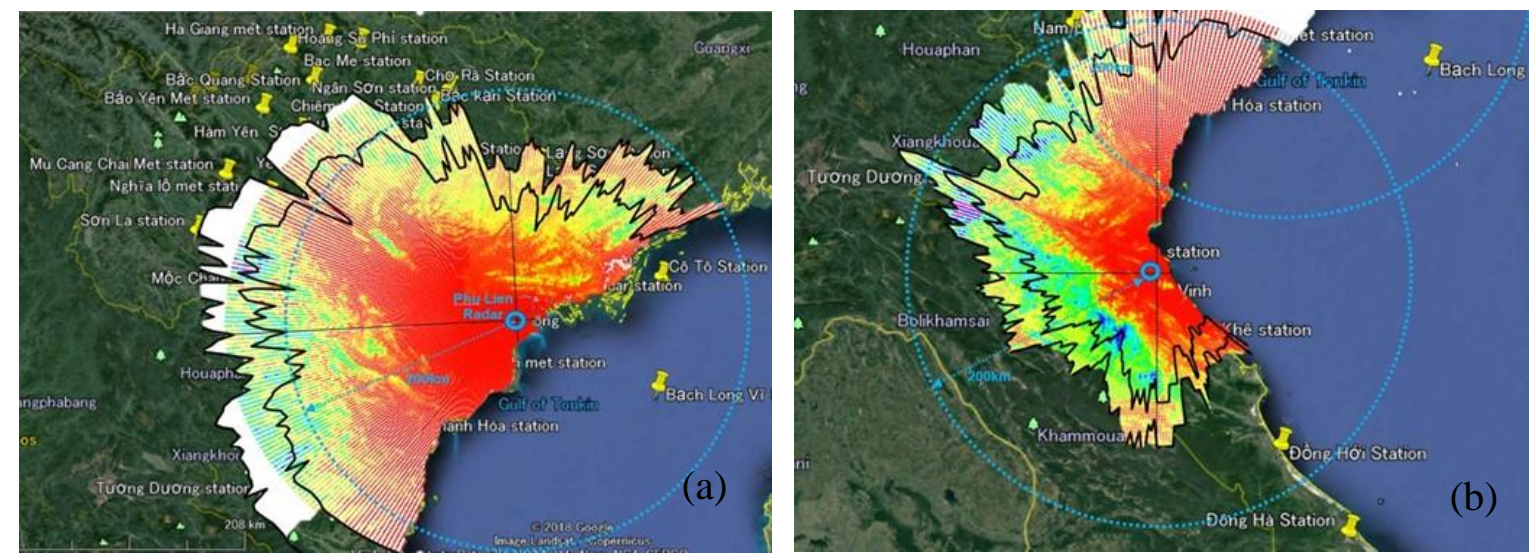

Figure 14. (a) Phu Lien; (b) Vinh radar-beam shadow diagrams.

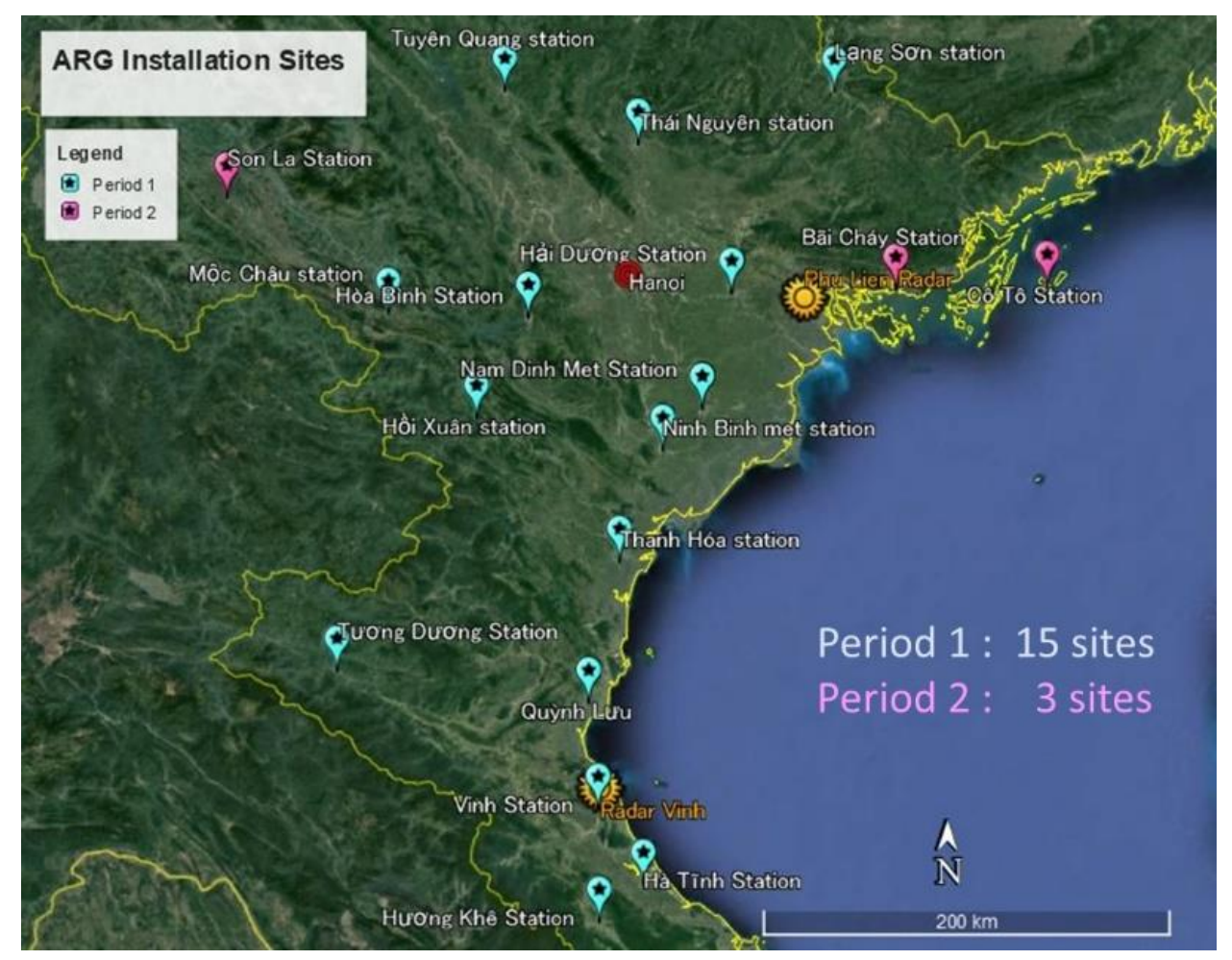

Figure 15. Map for ARG installation sites within Phu Lien and Vinh radar coverages.

\subsection{Design}

Most of design factors for ARG equipment were easily decided thanks to the site survey and experiences of ARG installation projects in other countries. On the other hand, telecom means from the equipment at local site to a data collection server in Hanoi and civil work 
design required additional study and deep considerations. The final design to procure ARG equipment is illustrated in Figure 16.

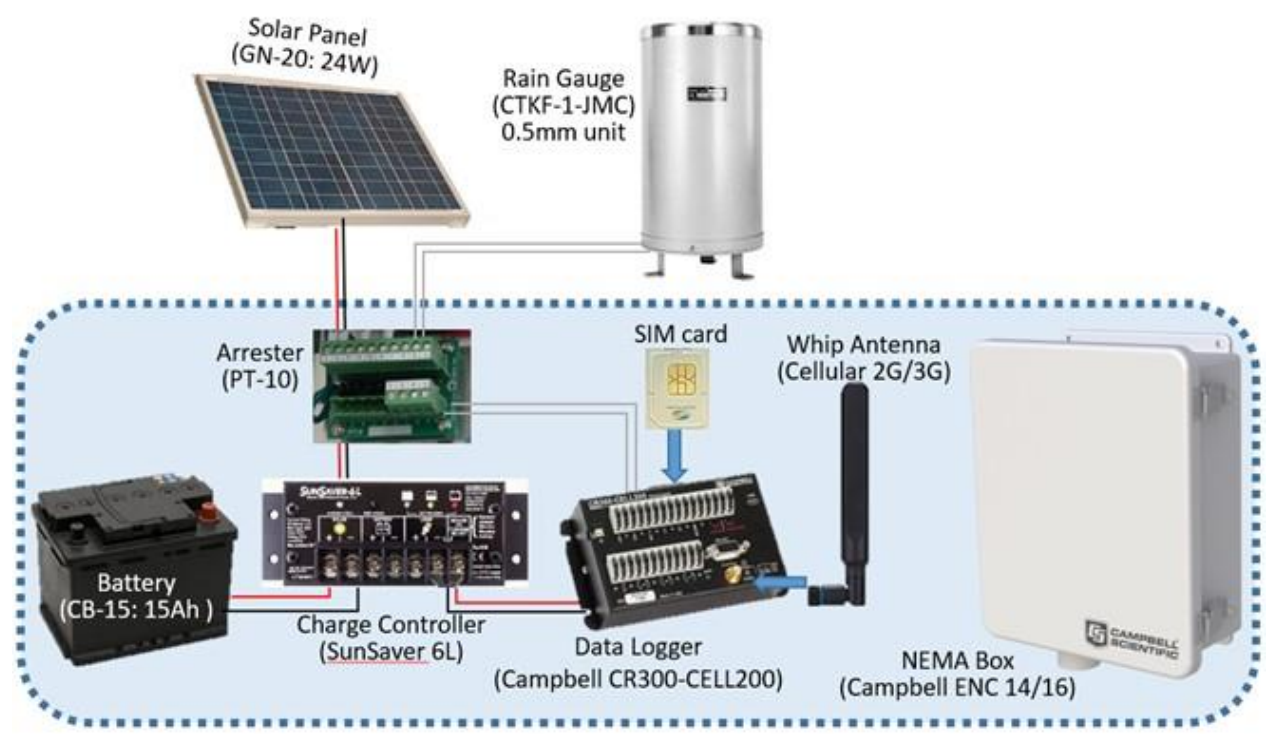

Figure 16. Design for ARG equipment.

To find most appropriate telecom means for ARG data collection, several options were studied such as Internet IP socket, email on the Internet via mobile networks, long distance Wi-Fi and Short Message Sending (SMS) on mobile telephone network. After the study, actual verification tests of a few options were implemented in November and December 2018. The Working Group with IDC experts discussed and finally decided a telecom means based on the test results as a real-time data collection network shown in Figure 17.

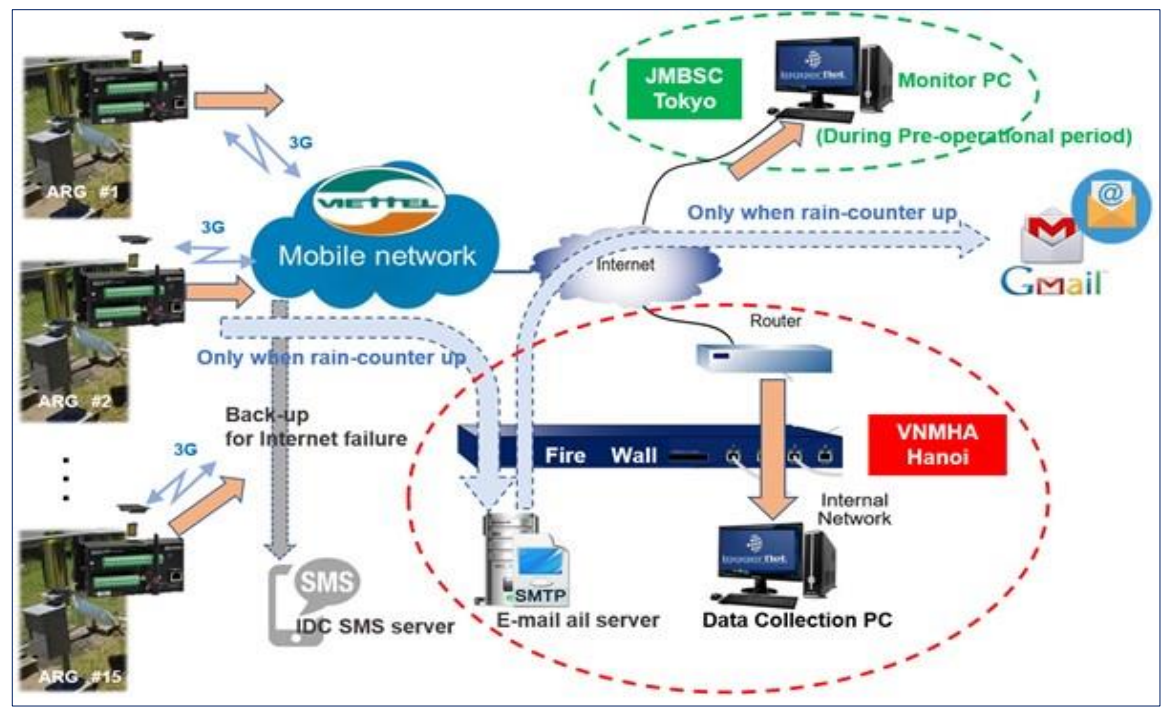

Figure 17. Design of ARG data collection network.

3G mobile network provided by Viettel is used for site access. Three telecom methods are configured to correct ARG data at every 10-minute interval. The main method is TCP Socket connection and the supplementary one is e-mail via the Internet. As the third one 
Short Message Sending (SMS) is used for backup when the collection via the Internet failures. To finalize the civil work, design the issues of foundations and stanchions were studied and concluded in cooperation with a constructive material manufacturer. In the site survey at North Central RHMC (Vinh), a new foundation and a stanchion preliminary manufactured were strictly evaluated by JICA experts and counterparts under the manufacturer stands. Figure 18 illustrates a final design for a foundation and a stanchion.

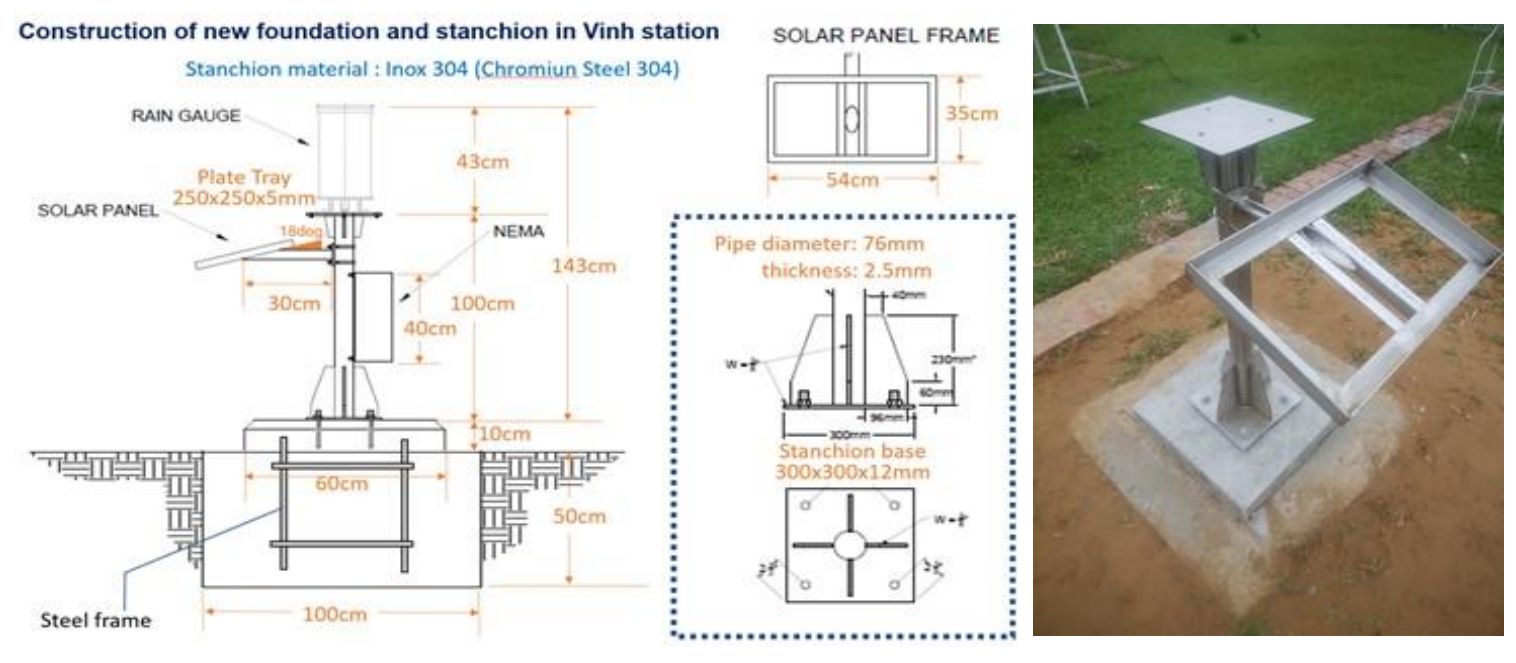

Figure 18. Foundation and stanchion for ARG (left: design drawing, right: real ones in Vinh).

\subsection{Preparation}

According to JICA guidelines, procurement of ARG equipment for installation in Period I of the project, development of data logger programs and functional inspection were implemented in Japan by the end of February 2019.

Although there was delay due to trouble of tax exemption procedures in shipping, 15 ARGs for Period I became available at VNMHA HQs in September 2019. Then VNMHA staff and JICA experts commenced practical preparation at VNMHA HQs such as acceptance test, procurement and establishment of data collection servers, development of installation guides and check list and schedule for the on-site installation. Figure 19 shows preparation examples.

Since 15 Rain Gauges of tipping bucket type at $0.5 \mathrm{~mm}$ unit were required accuracy and reliability, they were certificated by VNMHA as an item for the acceptance test in addition to the certification by JMA. 


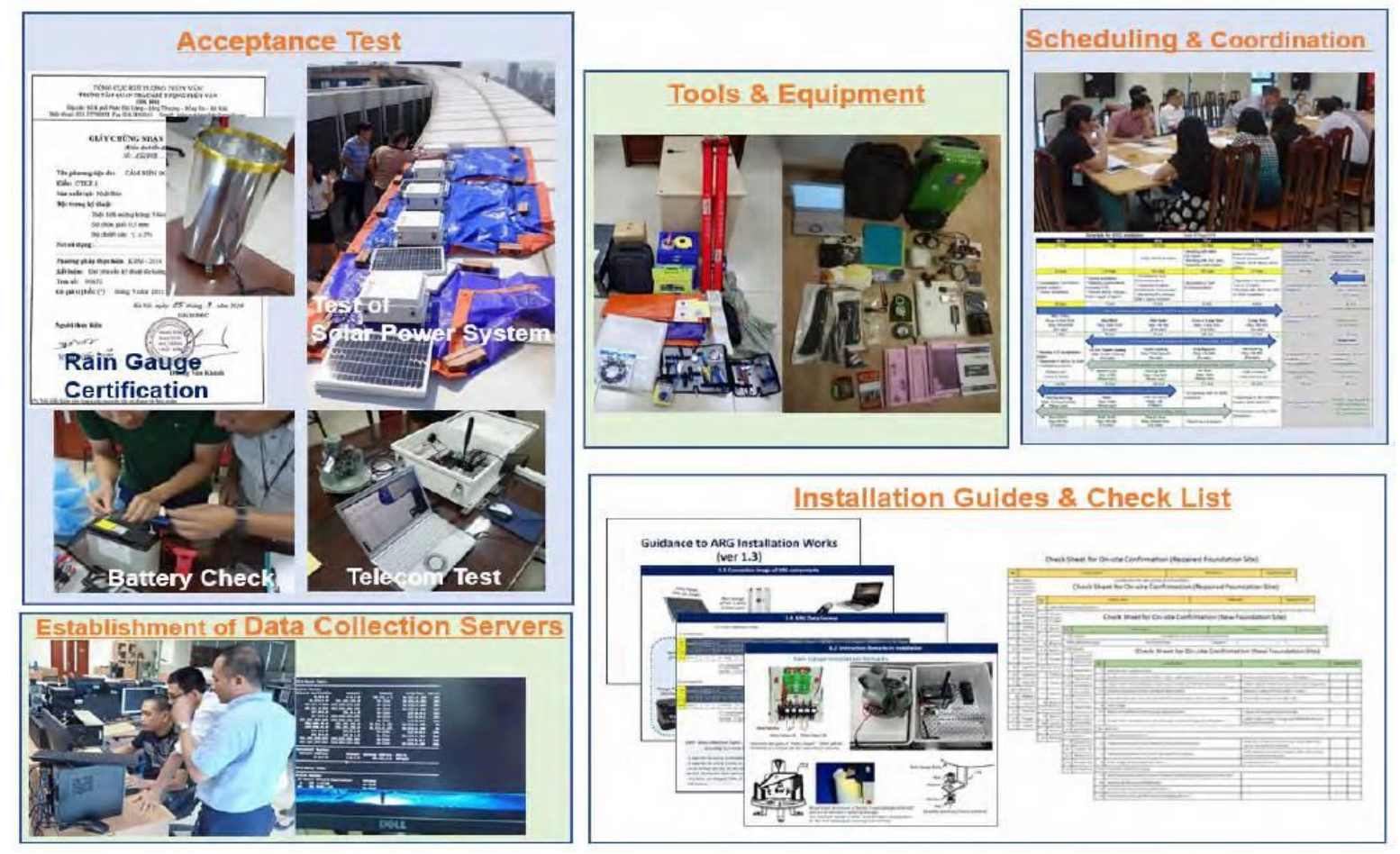

Figure 19. Preparation examples for ARG installation.

\subsection{Installation}

After reconfirmation of the civil work at 15 sites, two installation teams which consist of JICA experts and VNMHA staffs were formed and then conducted the installation parallelly in September and October 2019. Installation procedures were instructed in detail according to about 30 work items in the installation guide. At the same time technical transfer to VNMHA staffs including on-site observers was practically implemented through preliminary installation rehearsal and on-site OJT. Figure 20 shows installation works and pictures of on-site OJT.
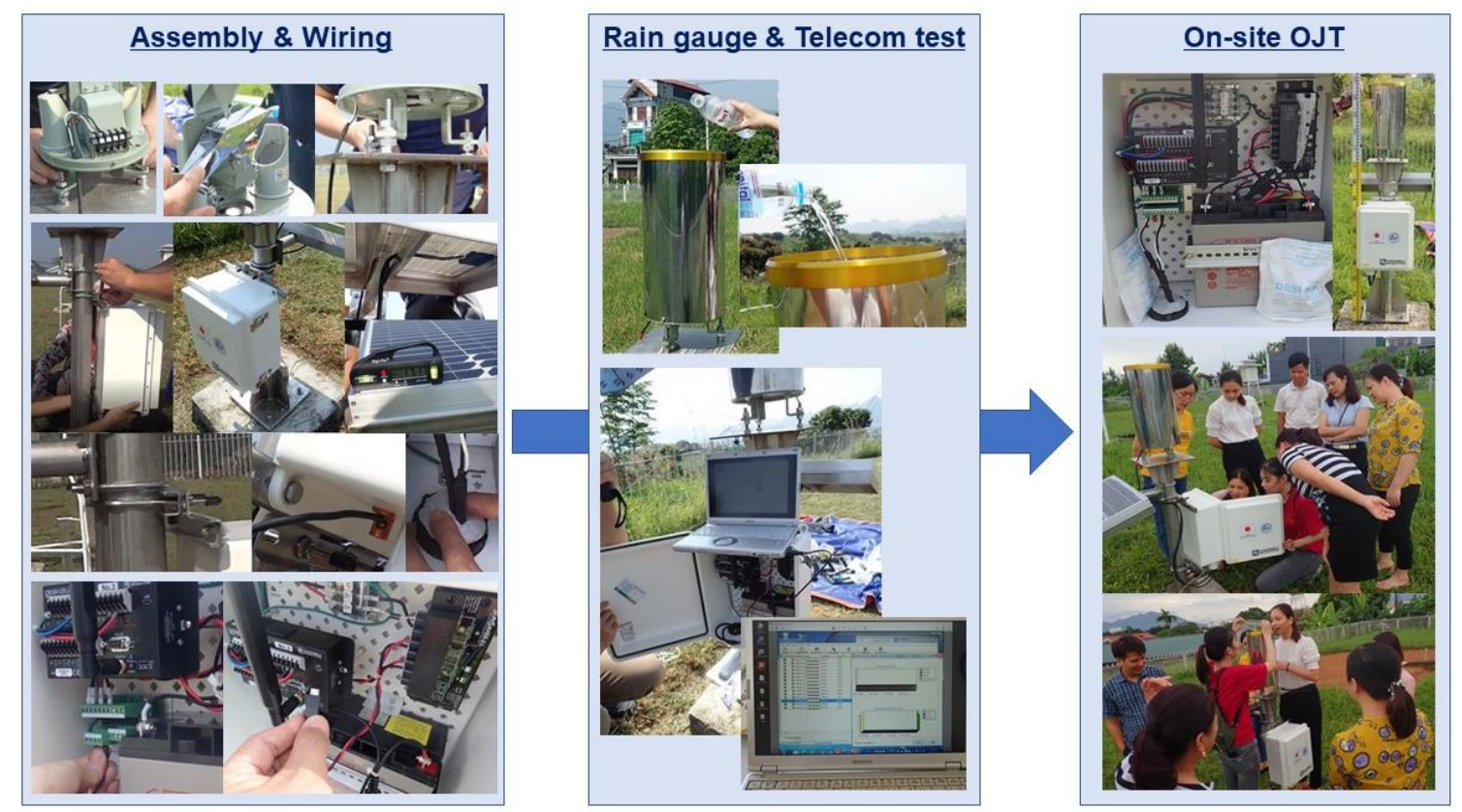

Figure 20. Installation works and on-site OJT. 


\subsection{Evaluation}

After installation of 15 ARGs for Period I and ARG data collection servers, the ARG network system entered the pre-operational phase from 19 October 2019. Thereby preoperating environment to use ARG data for radar calibration was established. JICA experts have been monitoring to evaluate the long-running status to adjust operational parameters towards official operation phase. The monitoring result is shown in Table 6.

Table 6. Monitoring results of the pre-operation.

\begin{tabular}{lrrrrrrrrr}
\hline \multirow{2}{*}{ Station Name } & \multicolumn{2}{c}{ Transmission Success Rate [\%] } & \multicolumn{2}{c}{ 3G Signal Intensity [dBm] } & \multicolumn{3}{c}{ Battery Voltage [V] } \\
\cline { 2 - 9 } MCP Socket & E-mail & SMS & max & min & ave & max & min & ave \\
\hline Moc Chau & 99.9 & 51.9 & 94.3 & -51 & -73 & -52 & 14.6 & 12.7 & 13.3 \\
Hoa Binh & 100.0 & 68.8 & 96.1 & -51 & -81 & -55 & 14.5 & 12.8 & 13.2 \\
Lang Son & 99.8 & 76.9 & 92.7 & -57 & -73 & -62 & 14.7 & 12.7 & 13.3 \\
Tuyen Quang & 99.9 & 58.0 & 89.7 & -51 & -63 & -53 & 14.6 & 12.7 & 13.2 \\
Thai Nguyen & 99.8 & 51.2 & 96.1 & -51 & -91 & -53 & 14.5 & 12.7 & 13.3 \\
Hai Duong & 91.5 & 54.3 & 0.9 & -51 & -85 & -73 & 14.5 & 12.8 & 13.3 \\
Nam Dinh & 100.0 & 79.8 & 76.2 & -61 & -69 & -64 & 14.5 & 12.8 & 13.3 \\
Ninh Binh & 99.9 & 52.0 & 77.3 & -51 & -69 & -59 & 14.5 & 12.8 & 13.3 \\
Hoi Xuan & 99.8 & 51.7 & 77.1 & -51 & -69 & -59 & 14.6 & 12.8 & 13.3 \\
Thanh Hoa & 100.0 & 70.7 & 60.3 & -51 & -69 & -55 & 14.5 & 12.6 & 13.3 \\
Tuong Duong & 99.8 & 54.0 & 71.2 & -55 & -69 & -61 & 14.6 & 12.7 & 13.2 \\
Quynh Luu & 97.2 & 49.7 & 77.1 & -57 & -91 & -75 & 14.5 & 12.8 & 13.3 \\
Vinh & 99.8 & 58.2 & 60.4 & -53 & -77 & -65 & 14.5 & 12.8 & 13.2 \\
Ha Tinh & 100.0 & 85.0 & 72.2 & -51 & -69 & -61 & 14.4 & 12.8 & 13.2 \\
Huong Khe & 99.9 & 66.6 & 65.7 & -51 & -87 & -75 & 14.5 & 12.5 & 13.2 \\
\hline
\end{tabular}

\section{Summary and Discussion}

On 17th of November 2017, VNMHA and JICA exchanged the Record of Discussion (R/D) for "the project for enhancement of capacity in weather forecasting and flood early warning system". In this project, a unified AWS maintenance report and calibration tools were proposed to enhance reliability of long-term operation of AWS and its observation accuracy.

By sharing the AWS unified maintenance report as a digital metadata file among the observation site, regional hydro-meteorological centers and VNMHA data center, it will be capable of maintaining and managing the AWS system and equipment for many years.

The proposed AWS calibration tools consist of digital barometer, digital Assmann ventilating psychrometer, and rain gauge calibmeter. Each instrument will be verified by the standard instruments of Instrumentation Center in Hanoi, Da Nang, and Ho Chi Minh to ensure traceability. Then, they are used for comparative observations with AWS instruments for the purpose of calibration of each sensor.

In addition to introducing measures at observation sites that we have seen so far, for the purpose of improving the reliability of AWS data, the following technical development can 
be considered as the next target. That is, a feasibility study for introduction of the QC and AQC technologies at the data center of VNMHA for the purpose of improving the reliability of AWS data. Currently, center QC of observation data collected in VNNHA's IDC is not performed, and there is a risk of missed preliminary warnings and false announcements due to data whose quality is not guaranteed. Currently, the AWS data format of each donor and the measurement time interval are not uniform, for this, it is a challenge to introduce AQC immediately. But there are rooms to make a technical consideration for introducing AQC as pre-process after archiving AWS data to IDC.

As we have seen, in order to calibrate the radar signals of Phu Lien and Vinh for the development of QPE, we have planned to install the ARG network totally 18 locations in this project. As of June 2020, we have already completed the installation at 15 locations.

Author Contributions: Analysis and writing-original draft preparation, Dr. Mikami, Mr. Matsubara, Mr. Ichijo, L.X. Duc and N.H. Anh; writing-review and editing, Dr. Mikami and Mr Ichijo; All authors have read and agreed to the published version.

Acknowledgments: This JICA technical cooperation project was supported by the people of Japan as JICA projects and technical assistances by JMA as DRR technical cooperation of WMO international cooperation frame for southeast Asian countries. Specific thanks to JICA Tokyo experts who supports the project and Meteorological and Hydrological Administration (VNMHA) who have joined in the JICA Project for Strengthening Capacity in Weather Forecasting and Flood Early Warning System in the Social Republic of Vietnam.

Conflict of interest: The authors declare no conflict of interest.

\section{References}

1. World Meteorological Organization. Guide to the Global Observing System, 2014, WMO-No.488; 1163p.

2. Harrison, R.G.; Wood, C.R. Ventilation effects on humidity measurements in thermometer screens. $Q$. J. R. Meteorol. Soc. 2012, 138, 1114-1120. DOI:10.1002/qj.985.

3. Nakai, S.; Yokoyama, K. The importance of the correction of wind-induced under catch of the gauges: The necessity for compilation of metadata on the gauges. Tenkii. 2009, 56, 11-16 (in Japanese).

4. Stull, R.B. An Introduction to Boundary Layer Meteorology. Kluwer Academic Publishers, Dordrecht, The Netherlands, 1988, pp. 376-389.

5. Searcy, J.K.; Hardison, C.H. Double-Mass Curves. Geological Survey WaterSupply Paper, 1960, 1541-B, 34-40. 